\title{
Study and Improvement of Reduction Retardation and Melt-down Properties of Pellets
}

\author{
Ichiro SHIGAKI,1) Shoji SHIROUCHI, ${ }^{2)}$ Kunihiko TOKUTAKE ${ }^{3)}$ and Nobuhiro HASEGAWA3)
}

1) Superconducting \& Cryogenic Technology Center, Kobe Steel, Ltd., Takatsukadai, Nishi-ku, Kobe, Hyogo-ken, 673-02. Development and Testing Center, Kobe Steel, Ltd., Wakinohama-cho, Chuo-ku, Kobe, Hyogo-ken, 651 Japan. Kobe Steel, Ltd., Kanazawa cho, Kakogawa, Hyogo-ken, 675-01 Japan.

2) Technical

(Received on April 5, 1989; accepted in the final form on September 8, 1989)

The reduction, carburization, and melt-down properties at high temperatures of pellets and sinter in packed beds were studied using a quenching method. The results obtained are summarized as follows:

(1) Reduction retardation of pellets is attributed to the disappearance of the micropores caused by sintering of iron uncer the presence of a liquid exuded from the wustite core.

(2) Carburization proceeds mainly through the diffusion of carbon from the iron surface, brought about by melting reduction, directly contacting solid carbon.

(3) Improved pellet reduction retardation was brought about by adjusting the chemical composition of the core part to have a higher solidus temperature. The melt-down property was ameliorated by increasing the basicity of the entire pellet.

KEY WORDS: reduction retardation; carburization; melt-down; pellet; sinter, under-load test.

\section{Introduction}

As a result of dissecting blast furnaces ${ }^{1,2)}$ the importance of the high temperature characteristics of agglomerates has been recognized, and it has been revealed that a reduction retardation of self-fluxed pellets is also caused by the addition of dolomite. With that in mind, the light pellet ${ }^{3}$ has been developed which is made by mixing sawdust with the green pellet material and, hence, revealed the relationship between the melt formation process and softening shrinkage in the reagent synthesis system. ${ }^{4}$ ) They have been endeavoring to improve the high temperature characteristics of ordinary dolomite pellets by adjusting their components. As to allow the high temperature characteristics of pellets reach those of iron ore sinter as a whole, it is necessary to clarify the reduction retardation mechanism and melt-down behavior.

This paper describes the results of research into the phenomena of reduction retardation, carburizing and melt-down done at Kobe Steel, Ltd. This research was conducted using small-sized reduction equipment under load, which can quench the dolomite pellets and sinter by immersing them in water. Based on the results, we experimentally made a two-layers pellet system which prevents reduction retardation by suppressing the sintering of metallic iron. This paper also discusses the characteristics of the under-load reduction test.

\section{Experimental Procedure}

Fig. 1 shows the quenching test equipment. It is made entirely of graphite. It consists of an ID 38 mm vessel to accommodate about $50 \mathrm{~g}$ of packed agglomerate, a slitted guide to, initially, hold the vessel and, then, to let it down; a skirt to prevent entry of the gas that flows through the slit; a blade to rotate the vessel; and a loading bar. The entire packed bed is let down into water placed under the electric furnace by this equipment so that a steady state of any required temperature can be observed. The shrinkage of the packed bed and pressure loss during the reduction process can be continuously measured. The reduction degree was determined by computing the material balance from the results of exhaust gas analysis, obtained by using an infrared ray analyzer. The testing conditions are given in Table 1. The samples are commercial dolomite pellets and sinter of Kakogawa Works. Their chemical compositions are given in Table 2.

The metallic iron sintering experiment and a quantitative analysis of the solidus in the reduction process were conducted using the procedure shown in Fig. 2. The slag composition in the sintering experiment was set at $\mathrm{CaO} 39.6, \mathrm{SiO}_{2} 30.4, \mathrm{MgO} 20.0$, $\mathrm{Al}_{2} \mathrm{O}_{3} 10.0 \mathrm{wt} \%$ based on the composition of the commercial pellets. The iron component was changed within the range of $58-68 \mathrm{wt} \%$ calculated as $\mathrm{T} . \mathrm{Fe}$ at an induration stage. The temperature at which the integrated value of pore diameters larger than $2 \mu \mathrm{m}$ becomes less than $0.02 \mathrm{~cm}^{3} / \mathrm{g}$ as determined by a pore size distribution is defined to be the stintering tempera- 


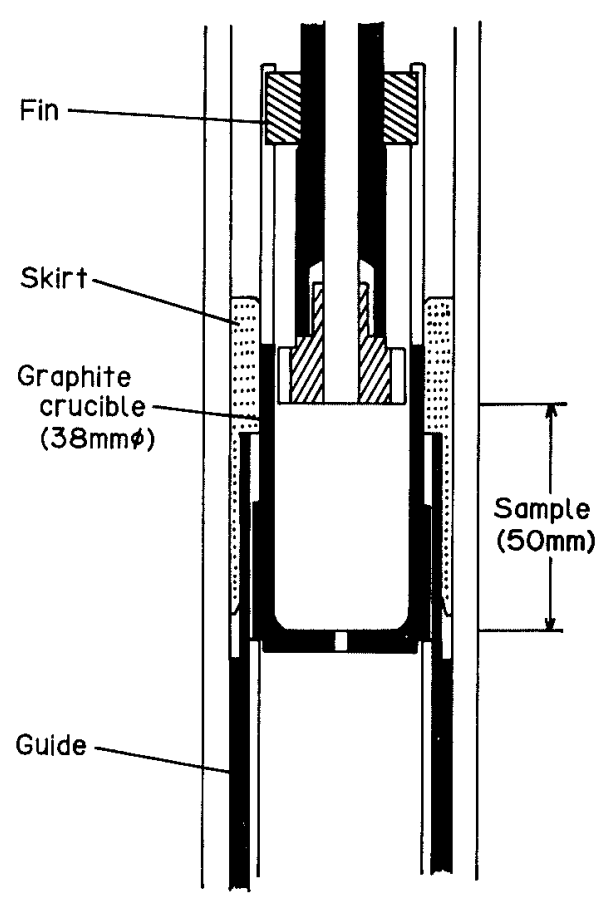

Fig. 1. Experimental apparatus for quenching samples during reduction.

Table 1. Experimental condition for under-load reduction test.

\begin{tabular}{lll}
\hline Heating rate & $\begin{array}{l}10^{\circ} \mathrm{C} / \mathrm{min} \\
\text { Holding for } 1 \mathrm{~h}\end{array}$ & $\begin{array}{l}\left(<900^{\circ} \mathrm{C}\right) \\
\left(900^{\circ} \mathrm{C}\right)\end{array}$ \\
& $5^{\circ} \mathrm{C} / \mathrm{min}$ & $\left(>900^{\circ} \mathrm{C}\right)$ \\
& $5 \mathrm{~N} l / \mathrm{min}$ & \\
Flow rate & $\mathrm{CO} / \mathrm{CO}_{2} / \mathrm{N}_{2}$ & \\
Composition of gas & $10.5 / 9.5 / 80$ & $\left(<600^{\circ} \mathrm{C}\right)$ \\
& Linear change & $\left(<900^{\circ} \mathrm{C}\right)$ \\
& $12 / 8 / 80$ & $\left(900^{\circ} \mathrm{C}\right)$ \\
& $20 / 0 / 80$ & $\left(>900^{\circ} \mathrm{C}\right)$ \\
& $47 \mathrm{~g}$ & \\
Sample weight & $45 \mathrm{~mm}$ & \\
Bed height & $9.8 \times 10^{4} \mathrm{~Pa}$ & \\
Applied load &
\end{tabular}

Table 2. Chemical compositions of samples for underload reduction test.

\begin{tabular}{lccccccc}
\hline Sample & $\mathrm{T} . \mathrm{Fe}$ & $\mathrm{FeO}$ & $\mathrm{MgO}$ & $\mathrm{Al}_{2} \mathrm{O}_{3}$ & $\mathrm{SiO}_{2}$ & $\mathrm{CaO}$ & $\begin{array}{l}\mathrm{CaO} / \\
\mathrm{SiO}_{2}\end{array}$ \\
\hline Pellet & 62.71 & 0.96 & 1.75 & 1.25 & $2.5 \mathrm{I}$ & 3.30 & 1.31 \\
Sinter & 56.67 & 5.33 & 0.96 & 1.65 & 5.46 & 10.09 & 1.85 \\
\hline
\end{tabular}

ture. The solidus temperatures of the reagent synthesis system have been determined by microscopic observation of quenched samples.

\section{Experimental Results and Considerations}

\subsection{Analysis of the Under-load Reduction Test of Sinter and Pellets}

Fig. 3 shows the results of the under-load reduction test of sinter and pellets at temperatures up to $1500^{\circ} \mathrm{C}$.

Sinter reduction (particle sizes of 10 to $13 \mathrm{~mm}$ ) occurred at a temperature of $500^{\circ} \mathrm{C}$ but there is less

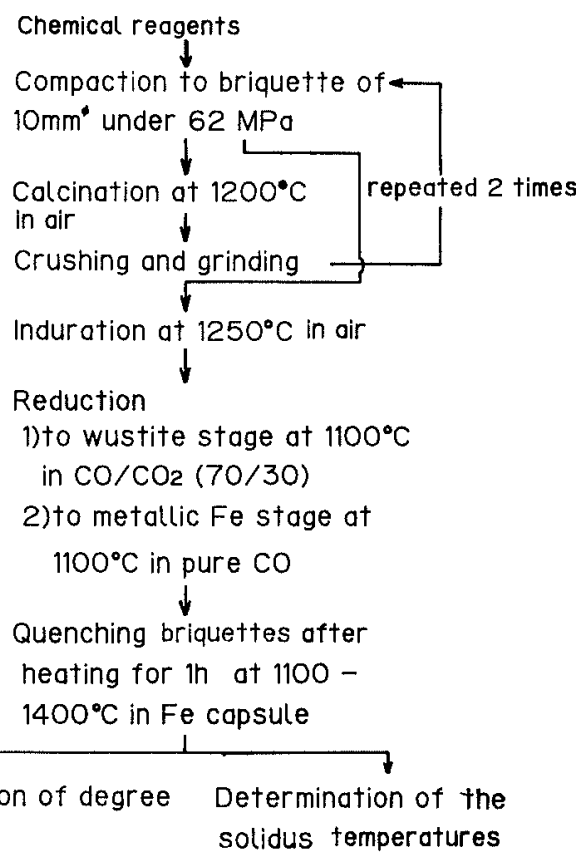

$\begin{array}{ll}\text { Determination of degree } & \text { Determination of the } \\ \text { of sintering } & \text { solidus temperatures }\end{array}$

measurement of pore

size distribution by $\mathrm{Hg}$

pressure porosimeter

Fig. 2. Experimental procedure to estimate the sintering degree and solidus in synthetic briquettes.

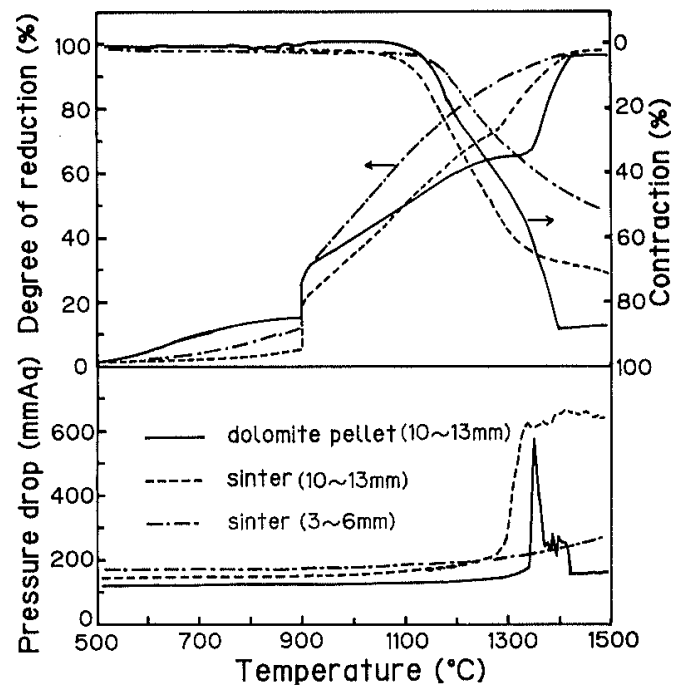

Fig. 3. Results of under-load reduction test for dolomite pellets and sinter.

reduction at temperature below $900^{\circ} \mathrm{C}$. Reduction to wustite at $900^{\circ} \mathrm{C}$ is not sufficient, and the inner part of the particle remains unreduced. However, at temperatures above $900^{\circ} \mathrm{C}$ reduction activity increases and continues to temperatures over $1200^{\circ} \mathrm{G}$. At $1280^{\circ} \mathrm{C}$ the wustite core begins abruptly to flow out, and the direct reduction speed increases remarkably. As a result, the reduction degree rises significantly. At this time pressure loss also increases remarkably, and the pressure loss is kept at a high level until meltdown occurs. After the temperature exceeds $1000^{\circ} \mathrm{C}$, the shrinkage of the bed continues as reduction progresses. At the high temperatures at which melting reduction occurs, the shrinkagesped is reduced. 
However, with small sinter particles, the gas reduction speed is high and the quantitative ratio of the wustite core to whole particle reduces before the temperature reaches $1280^{\circ} \mathrm{C}$, so that its influence is not negative on the advance of reduction. The pressure loss is also insignificant. This seems to correspond to the behavior of fine sinter particles which have been degraded in the blast furnace.

The reduction of pellets is activated above $600^{\circ} \mathrm{C}$. At temperatures of $900^{\circ} \mathrm{C}$ or below there is a significant difference in reduction degree between pellets and sinter. However, at temperatures above $900^{\circ} \mathrm{C}$ pellet reduction speed is fairly low when compared to that of sinter. At temperatures above $1200^{\circ} \mathrm{C}$ it shows even more significantly. Thus, the reduction retardation phenomenon appears. At $1350^{\circ} \mathrm{C}$ the melting reduction caused by the flowing-out of the wustite core occurs, and the amount of reduction increases suddenly. The relatively higher melting reduction degree and speed of pellets compared to sinter imply that there is a danger of blast furnace chilling. At this time pressure loss increases intensely, but this high pressure loss does not persist long. The pressure loss lessens as soon as the temperature rises. Pellet shrinkage is initiated later than sinter, at $1100^{\circ} \mathrm{G}$, and shrinkage is held to a low level. But after the melting reduction is initiated, the pellet layer abruptly shrinks, and totally melts down at $1440^{\circ} \mathrm{G}$.

\subsection{Structural Change in the Packed Bed due to Under- load Reduction}

Fig. 4 shows structural changes caused by the under-load reduction of large particles of sinter. Gas reduction of sinter is zonal, featuring a wide reaction interface. ${ }^{5)}$ From the macrostructural viewpoint it appears as a two-layers structure consisting of a metallic iron shell (shell part) and a wustite core as are pellets. However, since raw materials of corase particle are used for the sinter, the chemical composition and mineral structure are not uniform. At $1200^{\circ} \mathrm{C}$ the wustite core yet shows the structure of the induration stage, and the high basicity section has an acicular calcium ferrite structure but the low basicity section has a structure consisting of mainly iron ore. The high basicity section of the shell part has a structure consisting of mainly metallic iron and dicalcium silicate but the low basicity section has a structure consisting of metallic iron and silicate glass wherein the metallic iron is sintered forming coarse grains. The exudation (flowing-out moderately) of the wustite core from the sinter particles starts just before $1200^{\circ} \mathrm{C}$. At temperatures above $1280^{\circ} \mathrm{C}$ the flowing-out increases suddenly. Due to contact with the graphite, the melting reduction begins. Observation of the structure of the flowing-out section at $1350^{\circ} \mathrm{C}$ revealed that a great quantity of dicalcium silicate $\left(\mathrm{C}_{2} \mathrm{~S}\right)$, melilite and a small quantity of silicate glass exist around the iron particles generated by melting reduction. This impedes contact between the metallic iron and the graphite. At temperatures above $1380^{\circ} \mathrm{C}$ the wustite core disappears. At $1400^{\circ} \mathrm{C}$ the metallic iron of the flowing-out part becomes coarse although surrounded by high-melting slag.

The structure change in pellets was comprehensive-

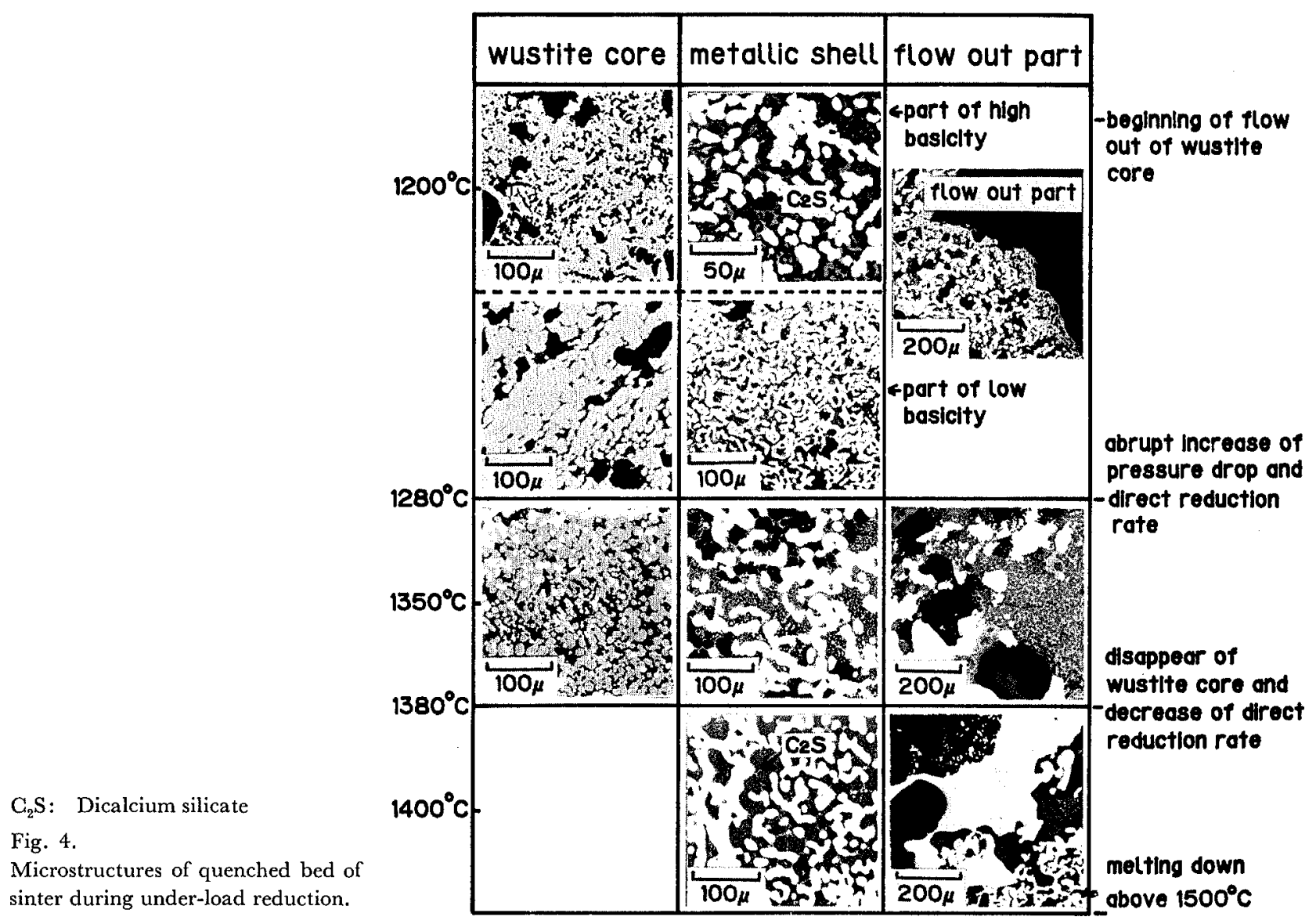


ly analyzed. ${ }^{6}$ Basically similar results were obtained in our experiments. Namely, gas reduction proceeds topochemically, forming a two-layers structure consisting of a metallic iron shell and a wustite core. At $1200^{\circ} \mathrm{C}$ or below a structure appears consisting of the metallic iron in which the slag phase is finely dispersed. The wustite core has a structure consisting of wustite and silicate glass containing $\mathrm{C}_{2} \mathrm{~S}$. At temperatures above $1300^{\circ} \mathrm{C}$ the flowing-out of the wustite core is activated, at $1350^{\circ} \mathrm{C}$ intensive melting reduction occurs, and the metallic iron of the flowing-out portion becomes coarse. At $1370^{\circ} \mathrm{C}$ this metallic iron and melilite slag begins to flow down.

\subsection{Changes in the Pore Structure of Pellets}

The changes in the pore structure of sinter in the blast furnace has previously been reported $^{7)}$ but as yet there has been scarcely any study regarding the pellets.

Fig. 5 shows how the open pore diameters in pellets change during the course of under-load reduction.

(a) After the sample was reduced to wustite at $900^{\circ} \mathrm{C}$, its temperature was raised in a $\mathrm{N}_{2}$ atmosphere under load simulating behavior of wustite core part.

(b) After the sample was reduced completely to metallic iron below $1000^{\circ} \mathrm{C}$, the under-load reduction

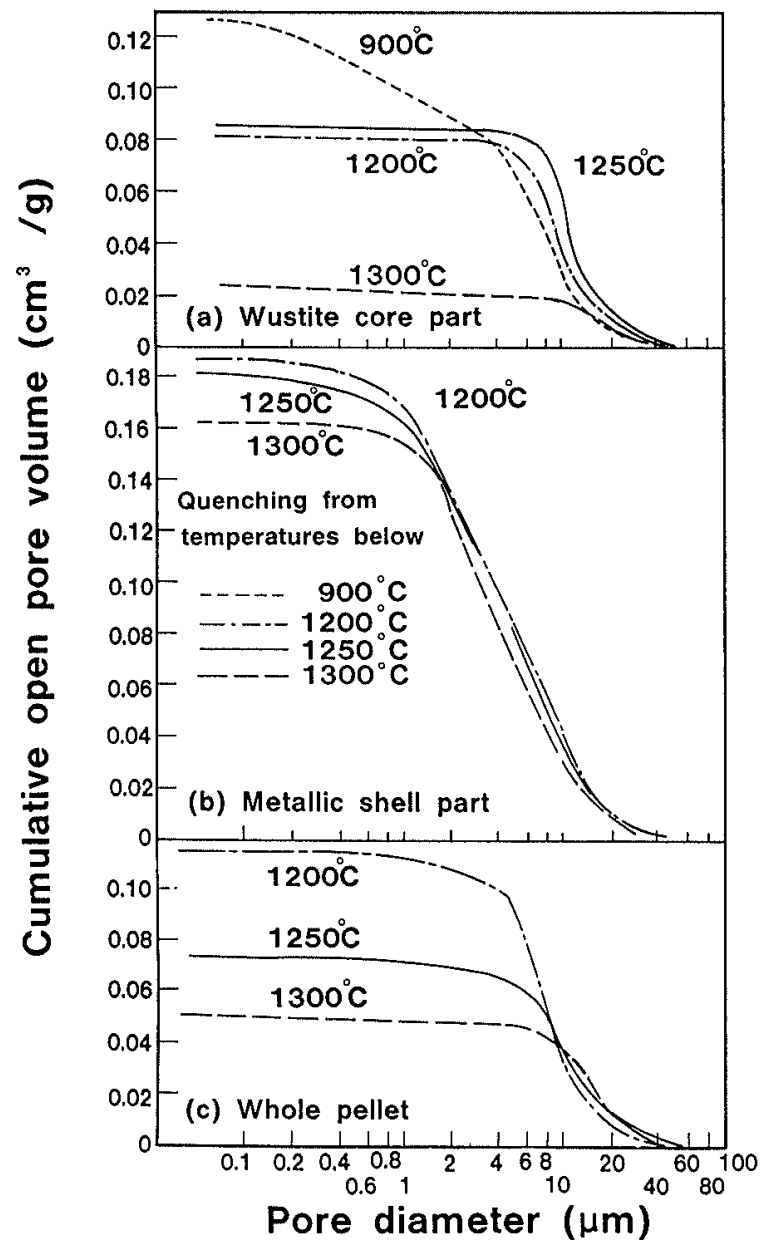

Fig. 5. Change of open pore volume of wustite core part, metallic shell part and whole pellets. test was performed simulating behavior of metallic shell part.

(c) The sample was prepared under the standard conditions in Table 1 corresponding to behavior of whole pellets. At the induration stage, pores smaller than $4 \mu \mathrm{m}$ are very few in number but during the process of being reduced to wustite these tiny pores increase. However, if the temperature exceeds 1200 ${ }^{\circ} \mathrm{C}$, the pores of sample (a) which were formed due to reduction, disappear; and at $1300^{\circ} \mathrm{C}$ pores larger than $10 \mu \mathrm{m}$ also decrease in number. Sample (b) has more pores in number smaller than $4 \mu \mathrm{m}$ than (a) $900^{\circ} \mathrm{C}$ sample. It is evident that the number of fine pores increase due to the reduction from wustite to metallic iron. As the temperature rises above $1200^{\circ} \mathrm{C}$, the solid state sintering of the metallic iron occurs, so that pores smaller than $1 \mu \mathrm{m}$ decrease in number but larger pores are not affected. In sample (c) pores smaller than $4 \mu \mathrm{m}$ exist at $1200^{\circ} \mathrm{C}$ but they completely disappear at $1250^{\circ} \mathrm{C}$. The extent of decrease in the total pore numbers in this sample is also higher than the sample (a) from 1200 to $1250^{\circ} \mathrm{C}$.

Thus, it has been shown that as the reduction to metallic iron through wustite proceeds, fine pores are formed. But at temperatures higher than $1200^{\circ} \mathrm{C}$, the metallic iron of the shell part is sintered under a presence of liquid as shown in Fig. 6, owing to the flow-out of slag from the wustite core, thereby resulting in a significant decrease in the number of pores.

Fig. 7 shows the extent the samples were sintered. At temperatures below $1200^{\circ} \mathrm{C}$ the reduction test was performed under standard conditions, while at higher temperatures the tests were done in a $\mathrm{N}_{2}$ atmosphere. Apparent density and compressive strength at room temperature were then measured. Although reduction does not progress at temperatures above $1200^{\circ} \mathrm{G}$, the apparent density increases at $1250^{\circ} \mathrm{C}$, and the compressive strength also increases, thereby proving that the sintering has progressed.

Fig. 8 shows the results of the chemical analysis of the components obtained by the mechanical separation of the shell part and the core part of the pellet as they occurring in the course of reduction. So as to compare the components, $\mathrm{Fe}^{2+}$ was calculated as M.Fe. This proves that the $\mathrm{CaO}$ and $\mathrm{SiO}_{2}$ content in the core part is lower than the content in the shell part at $900^{\circ} \mathrm{C}$, at which no melt exists. This implies that in the pelletizing process the seed rate from the iron ore is higher than from gangue or limestones. The components are the same at 900 and $1200^{\circ} \mathrm{C}$. At $1250^{\circ} \mathrm{C}$ the $\mathrm{CaO}$ and $\mathrm{SiO}_{2}$ content of the shell part increases a small amount but its content in the core part decreases. The $\mathrm{MgO}$ content shows the reverse trend. This may be attributed to the fact that the most of $\mathrm{MgO}$ is dissolved as a solid solution in wustite. The difference in the composition at $1300^{\circ} \mathrm{C}$ becomes more notable. Thus it has been revealed that the silicate melt formed in the wustite core part begins to exude into the shell part at temperatures above $1200^{\circ} \mathrm{C}$.

As mentioned above, a small amount of increased slag from 1200 to $1250^{\circ} \mathrm{C}$ did not induce any change 


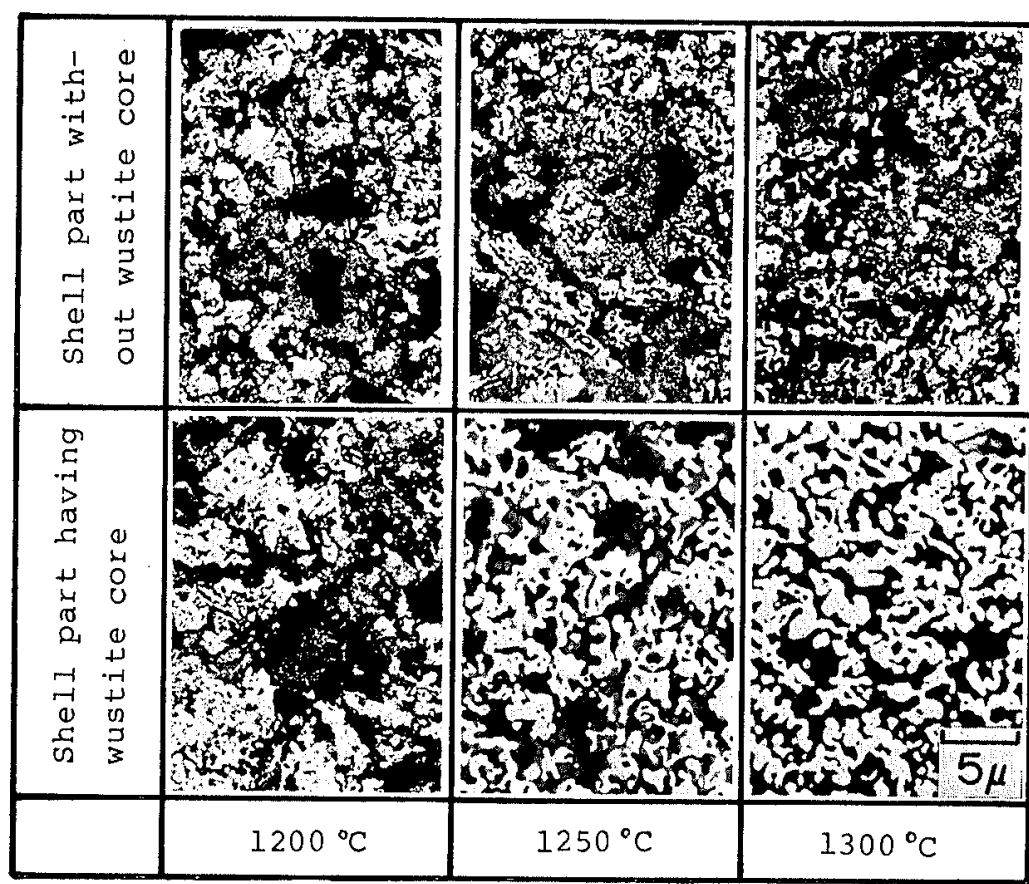

Fig. 6. Change in microstructure of shell part with the existence of wustite core.

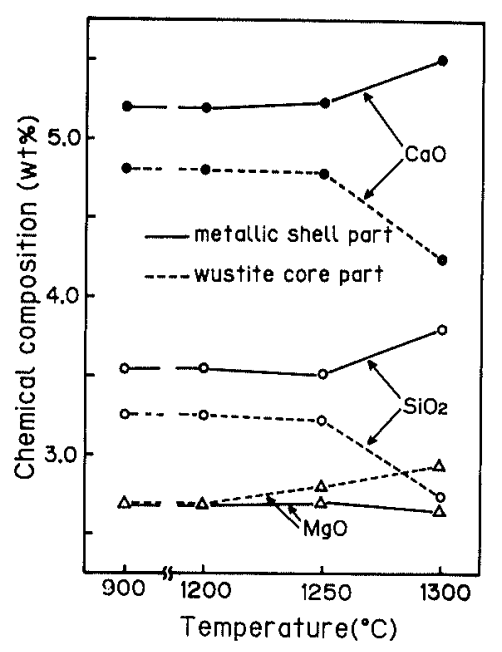

Fig. 8. Difference in chemical compositions between metallic shell part and wustite core part.

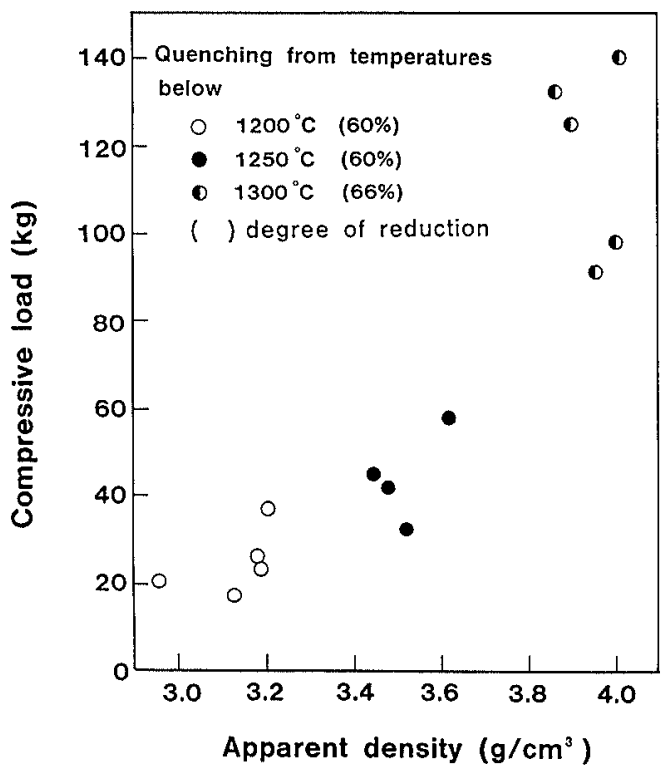

Fig. 7. Apparent density vs. compressive load of breakage of single pellets sintered after under-load reduction. Composition of gas was standard below $1200^{\circ} \mathrm{C}$ and pure $\mathrm{N}_{2}$ above $1200^{\circ} \mathrm{C}$.

of pore size distribution at wustite core part, but smaller amount of flown-out slag leads to change considerably at whole pellets. This fact indicates that significant decrease in the number of pores occurred mainly by sintering of metallic iron, but not by flownout of slag. These results allowed us to discover the mechanism of reduction retardation as shown in Fig. 9. The process proceeds as follows. At first, the melt formed in the wustite core part exudes into the shell part under the influence of capillary force. When the liquid phase fills in pores between metallic iron particles, each interparticle space becomes a capillary in which a substantial capillary pressure is developed. This pressure results in densification by

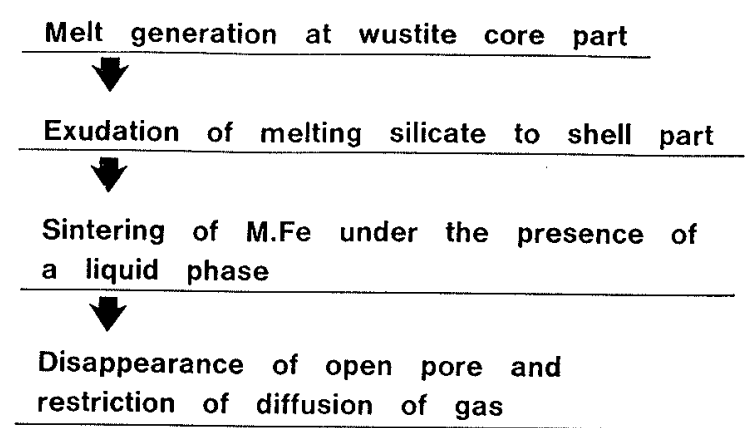

Fig. 9. Reduction retardation mechanism for pellets at high temperatures.

rearrangement of particles and high local stresses at bridges between contact particles. Then the metallic iron in this section is sintered, so that the fine pores disappear, thereby impeding reduction gas diffusion and, consequently, causing retardation.

\subsection{Carburization and Melting-down}

The melt-down of ores determines the inner shape of the cohesive zone of the blast furnace and affects the permeability and distribution of gas there. Inoue et al. $\left.{ }^{6}\right)$ revealed that the iron largely grown by melting reduction is carburized by contact with carbon and there is an inverse correlation which can be expressed by the following equation between the surface carbon concentration and the $\mathrm{FeO}$ content in the coexisting slag melt:

$$
\mathrm{FeO}(l)+\underline{\mathrm{C}}=\mathrm{Fe}(s)+\mathrm{CO}
$$

Fig. 10 shows FeO concentration in the slag melt of the cohesive iron section. FeO concentration increases as temperature rises. The results we obtained differ significantly from the results of Inoue et al., ${ }^{4}$ ) where $\mathrm{FeO}$ concentrations are much lower than those in this experiment and its tendenc with temperature 


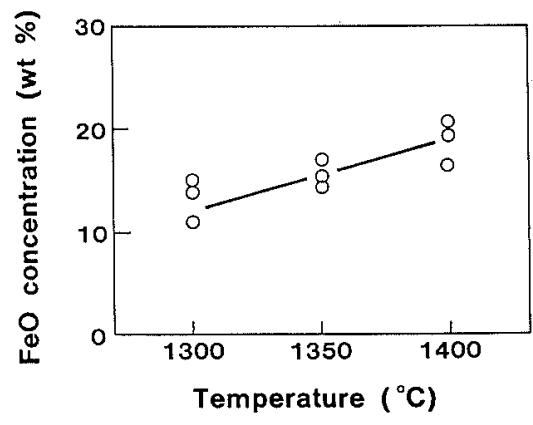

Fig. 10. Temperature dependence of $\mathrm{FeO}$ concentration in glassy silicate of metallic shell part of pellets.

is downward, and the equilibrium-based calculation data. Consequently this fact raises a question to a theory that carburization is determined by the equilibrium between carbon content in iron by melting reduction and $\mathrm{FeO}$ concentration in glassy silicate. With sinter, it was impossible to determine quantitatively the $\mathrm{FeO}$ concentration in the slag melt by EPMA since fine wustite crystallized in the slag melt.

Fig. 11 shows the carbon concentration distribution in the cohesive pellet iron at $1370^{\circ} \mathrm{G}$. A zone between the external surface that contacts the carbon source and the internal $25 \mu \mathrm{m}$ part consists of only $\mathrm{Fe}-\mathrm{C}$ melt which intermittently contacts the $\gamma$-Fe+ liquid range. Accordingly, once $\mathrm{Fe}-\mathrm{G}$ melt is formed in the zone in contact with the carbon source under a condition where the metallic iron cohesion is not impeded by slag, carburizing occurs suddenly to cause melt-down. With sinter, the carbon concentration is less than $0.5 \mathrm{wt} \%$ at $1500^{\circ} \mathrm{C}$, and carburizing from solid carbon does not occur.

The melting reduction process of the slag containing $\mathrm{FeO}$ is inferred to be as follows, based on the phase diagrams: A $2 \mathrm{CaO} \cdot \mathrm{SiO}_{2}-2 \mathrm{CaO} \cdot \mathrm{Al}_{2} \mathrm{O}_{3} \cdot \mathrm{SiO}_{2}$ FeO system ${ }^{8)}$ shown in Fig. 12 (a), a $\mathrm{CaO} \cdot \mathrm{SiO}_{2}-2 \mathrm{CaO}$. $\mathrm{Al}_{2} \mathrm{O}_{3} \cdot \mathrm{SiO}_{2}-\mathrm{FeO}$ system ${ }^{8)}$ also shown in Fig. 12(b). The slag component of the sinter corresponds to Fig. 12(a). Let us assume that when the slag composition of the wustite core matches with point $\mathrm{L}$ at $1300^{\circ} \mathrm{C}$ the melt flows out into the packed bed. Since the melt contacts the carbon source and melting reduction occurs, FeO concentration is reduced to reach point $\mathrm{M}$. If the reduction of the $\mathrm{FeO}$ component progresses, the $\mathrm{C}_{2} \mathrm{~S}$ begins to crystallize, and the melt composition changes from point $\mathrm{N}$ to point $\mathrm{P}$ on the eutectic line but it does not go beyond point $P$. The average composition of the melt and $\mathrm{C}_{2} \mathrm{~S}$ in this state is indicated by point $O$. If the temperature rises further, reduction of the $\mathrm{FeO}$ component and crystallization of the $\mathrm{C}_{2} \mathrm{~S}$ progress, the melt composition shifts towards the low $\mathrm{FeO}$ content side on the eutectic line, and as a result, the composition at $1400^{\circ} \mathrm{C}$ reaches point $\mathrm{R}$. Thus, in the case of sinter $\mathrm{C}_{2} \mathrm{~S}$ with its high melting point, crystallizes. This impedes physical contact between the metallic iron and the solid carbon as shown in Fig. 6, thereby resulting in suppressing carburization and the cohesion of the metallic iron. Accordingly, the metallic iron, whose melting point is lowered a little due to carburizing from the gas, be-

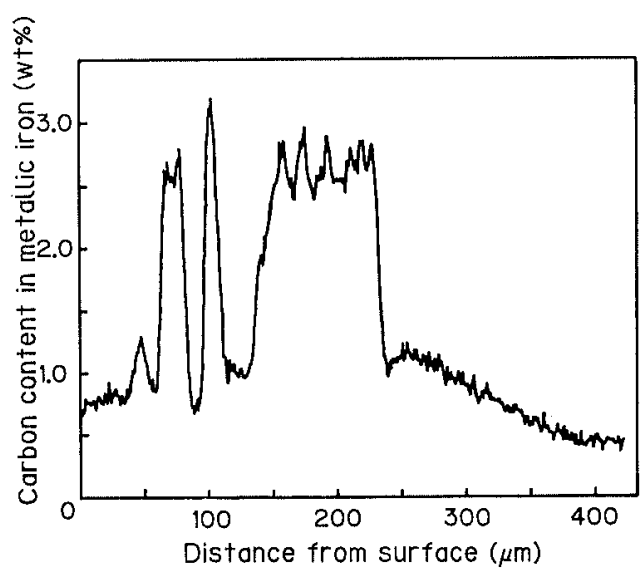

Fig. 11. Carbon concentration profile in the metallic iron of pellets formed by melting reduction at $1370^{\circ} \mathrm{C}$.
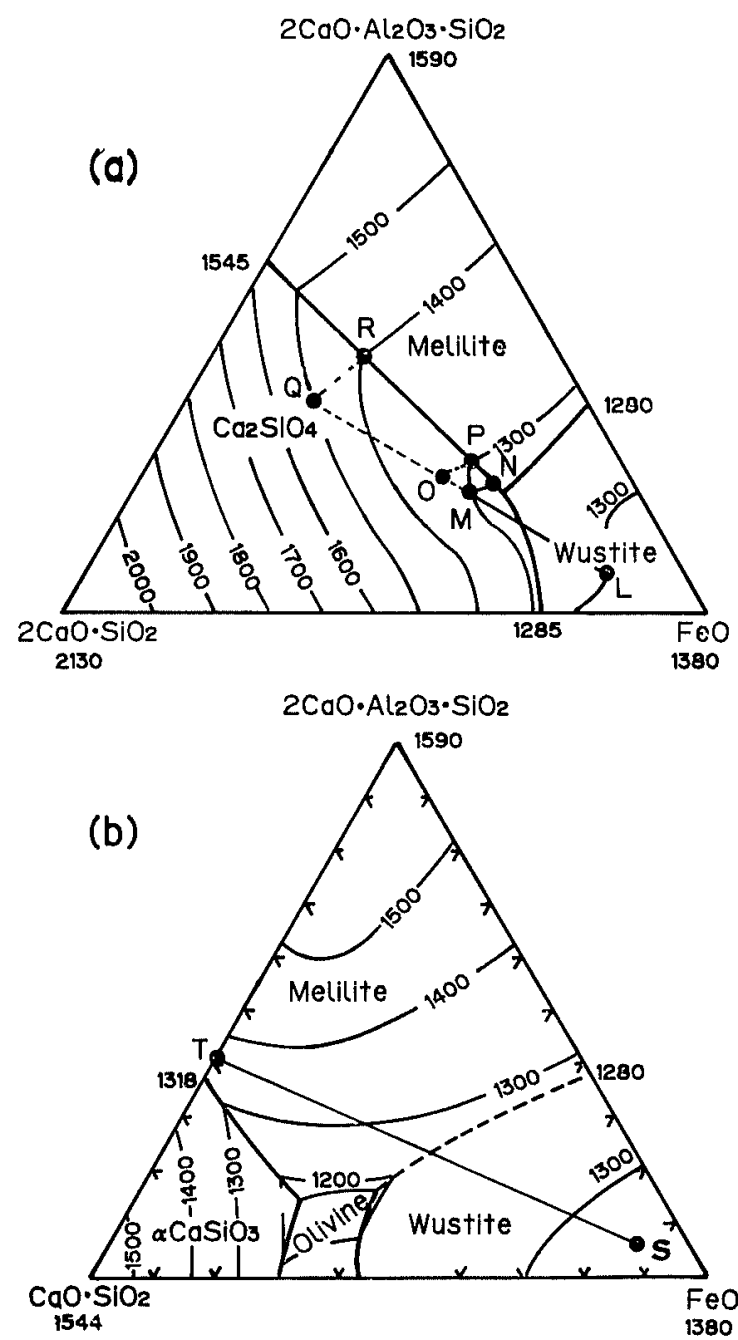

Fig. 12. Crystallization paths of flowed out liquids in $\sin$ ter (a) and pellets (b) due to melting reduction.

comes melt at $1500^{\circ} \mathrm{C}$ or above and melt-down is initiated.

On the other hand, the melting reduction process of pellets can be easily seen in Fig. 12(b). When the slag composition of the wustite core reaches point $S$ at $1350^{\circ} \mathrm{C}$, the melt begins to flow out into the packed bed. While the metallic iron is crystallized, the melt composition shifts to point $\mathrm{T}$ on the low $\mathrm{FeO}$ content 
side of the equi- $\mathrm{CaO} / \mathrm{SiO}_{2}$ line. Hence cohesion and melt-down of this melilite slag occur. The solid carbon and metallic iron are in contact continually, so that the melt is formed abruptly, and the whole bed melts down. Thus, it has been revealed that carburizing into metallic iron and melting-down are affected by the melting point of the slag. ${ }^{11}$

\subsection{Solid State Sintering of Metallic Iron}

As has been mentioned in the previous discussion, reduction retardation is caused as the melt formed in the wustite core is exuded into the shell part; this induces sintering of the metallic iron under the presence of a liquid. To suppress the formation of melt in the wustite core, Inoue et al.4) attempted to improve the softening and shrinkage properties by adjusting the core composition of the two-layers pellet to a higher T.Fe content $(66.6 \%)$. Actually, pellet shrinkage characteristics have been improved as a result of the decrease in generated melt but there remains the necessity to improve the reduction retardation characteristics. In an actual under-load reduction test conducted here of T.Fe $69 \%$ pellets, gas reduction retardation was observed at $1200^{\circ} \mathrm{C}$.

The influence of T.Fe on the solid state sintering of metallic iron tested for synthesized briquette has been examined using the procedure shown in Fig. 2 and the obtained results have been partially plotted in Fig. 13. Since reduction retardation occurs when fine pores smaller than $2 \mu \mathrm{m}$ disappear, the temperature at which the integrated value of pore diameters larger than $2 \mu \mathrm{m}$ becomes less than $0.02 \mathrm{~cm}^{3} / \mathrm{g}$ as determined by a pore size distribution measurement with a mercury pressure porosimeter is defined to be the sintering temperature. The resulting data have been plotted in Fig. 14. The temperature at which the metallic iron suddenly becomes coarse (adopted

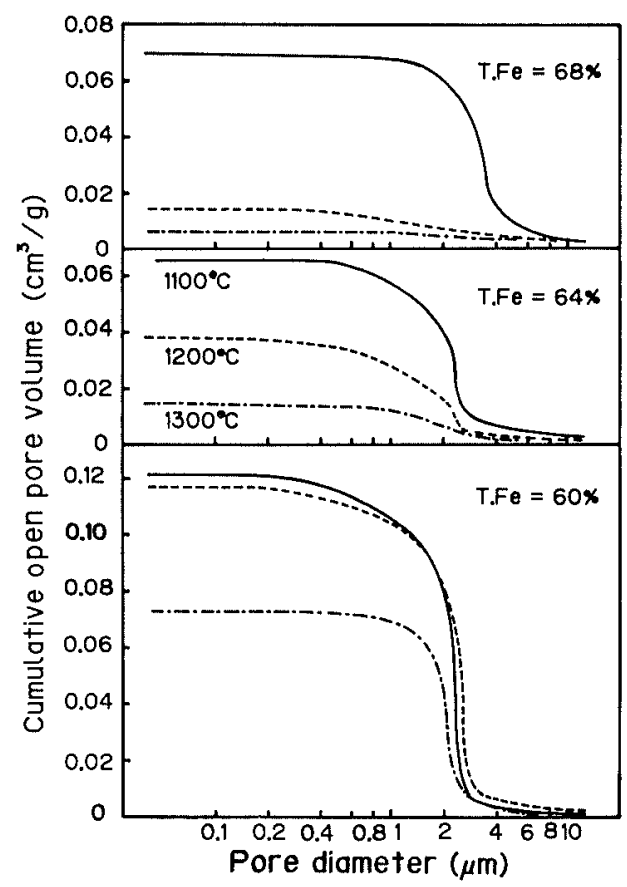

Fig. 13. Change of sintering degree with temperature and T.Fe of samples. from Inoue et $a l .^{4)}$ ) is also indicated. The metallic iron coarsening temperature seems to correspond to the slag melting point if the T.Fe is less than $64 \%$. On the other hand, the sintering temperature defined by pore size distribution lowers as the iron content increases since the frequency of contact of the metallic iron particles increase. Accordingly, an increase of T.Fe content reduces the quantity of generated melt in the wustite stage but promotes solid state sintering of the metallic iron in the metallic iron stage, as a result of which pore closing and reduction retardation are caused.

\subsection{Solidus Temperature of the $\mathrm{MgO}-\mathrm{Al}_{2} \mathrm{O}_{3}-\mathrm{SiO}_{2-}$ $\mathrm{CaO}-\mathrm{FeO}$ System}

It has been revealed that the formation of melt in the wustite core causes reduction retardation of pellets. The results of the under-load reduction test revealed that retardation is initiated just after the formation of melt at about $1200^{\circ} \mathrm{C}$. Accordingly, in

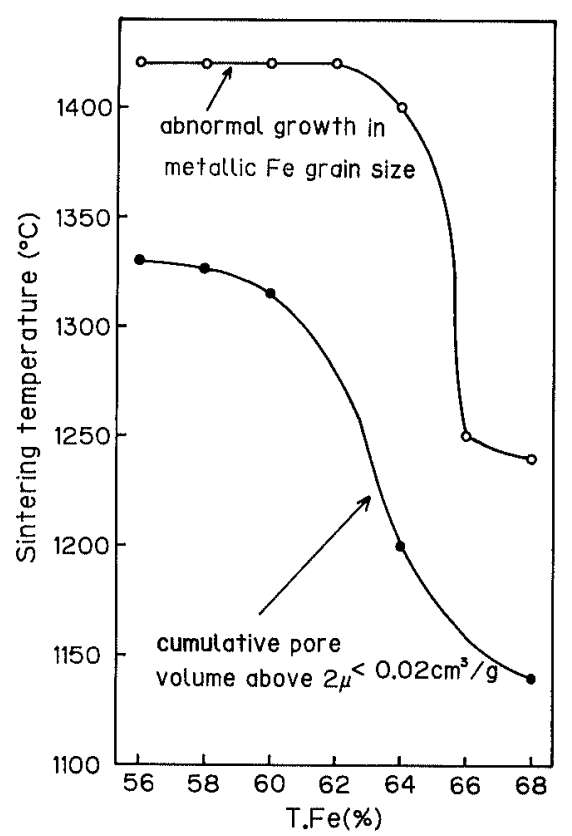

Fig. 14. Effect of T.Fe on the sintering temperature of briquettes.

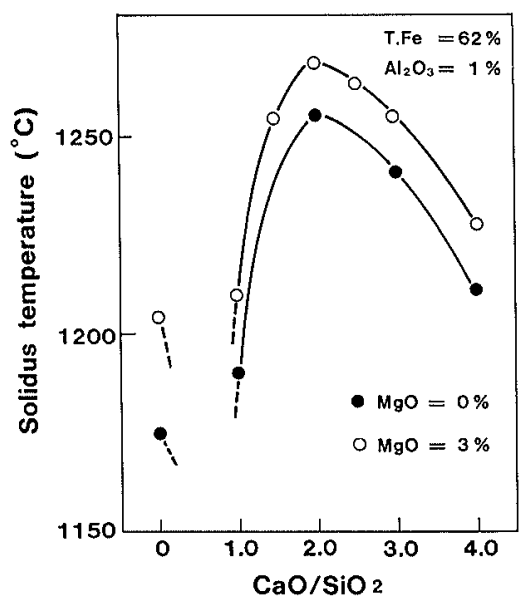

Fig. 15. Effect of $\mathrm{CaO} / \mathrm{SiO}_{2}$ and $\mathrm{MgO}$ on the solidus temperature of specimens reduced at the wustite stage. 
Table 3. Structure and chemical compositions of the two-layers pellets.

\begin{tabular}{|c|c|c|c|c|c|c|c|c|c|}
\hline & \multicolumn{2}{|c|}{ Structure } & \multicolumn{7}{|c|}{ Chemical composition (wt\%) } \\
\hline & $\begin{array}{l}\text { Ratio } \\
(\text { wt } \%)\end{array}$ & $\begin{array}{l}\text { Diameter } \\
(\mathrm{mm})\end{array}$ & T.Fe & $\mathrm{FeO}$ & $\mathrm{MgO}$ & $\mathrm{Al}_{2} \mathrm{O}_{3}$ & $\mathrm{SiO}_{2}$ & $\mathrm{CaO}$ & $\mathrm{CaO} / \mathrm{SiO}_{2}$ \\
\hline Core part & 40 & $8-10$ & 61.9 & 0.1 & 2.95 & 1.04 & 2.41 & 5.11 & 2.1 \\
\hline Shell part & 60 & $10-12$ & 61.2 & 0.1 & 2.20 & 1.29 & 3.58 & 5.42 & 1.5 \\
\hline Whole pellet & & $10-12$ & 61.4 & 0.1 & 2.55 & 1.15 & 3.00 & 5.28 & 1.8 \\
\hline
\end{tabular}

the formation of melt in the wustite core, the solidus is more important than the liquidus. The solidus temperatures of the reagent synthesis system under the conditions of $\mathrm{T} . \mathrm{Fe}=62 \%$ and $\mathrm{MgO}=0$ and $3 \%$, respectively, have been determined by the microscopic observation after quenching, and the obtained results have been plotted in Fig. 15. As is presumed from the 3-component phase diagram of $\mathrm{CaO}-\mathrm{FeO}-\mathrm{SiO}_{2},{ }^{9}$ ) the solidus has the highest value when $\mathrm{CaO} / \mathrm{SiO}_{2}=2$ irrespective of the existence/nonexistence of $\mathrm{MgO}$. An increase in $\mathrm{MgO}$ is effective for the rise of solidus. An addition of $3 \% \mathrm{MgO}$ when the $\mathrm{CaO} / \mathrm{SiO}_{2}=2$ causes it to be raised by $15^{\circ} \mathrm{C}$ or so.

\subsection{Improvement in High Temperature Characteristics with Two-layers Pellets}

As stated above, the chemical composition of the pellet must be modified for raising the solidus in the wustite stage under $\mathrm{CaO} / \mathrm{SiO}_{2}=2$ conditions and a high $\mathrm{MgO}$ content. To raise the melting-down temperature, it is necessary to raise the melting temperature of non-FeO slag formed by melting reduction. Therefore, in this respect too, $\mathrm{CaO} / \mathrm{SiO}_{2}=2$ is suitable. Nevertheless, it has been reported that the high basicity pellet degraded only with difficulty during low temperature reduction. ${ }^{10)}$ In our preliminary experiment it was proved that the RDI (Reduction Degradation Index) becomes worse if the basicity rises above 1.6. If pellet cracking and degradation are insignificant, low temperatures reduction is restricted on the external surface of the pellet. Hence, using a testing pot, we experimentally made two-layers pellets as shown in Table 3 ; its shell part has a composition exhibiting high resistance to low temperature degradation at a relatively low basicity and its core part has a high solidus composition with a $\mathrm{CaO} / \mathrm{SiO}_{2}=2$ and a high $\mathrm{MgO}$ content. The two-layers structure did not cause any problems with pelletizing. The obtained pellets have a compressive strength equal to that of ordinary pellets. RDI is 2.9 which is low enough for charging in blast furnace. Fig. 16 shows the results of the under-load reduction test. The two-layers pellet system is based on the fact that the reduction retardation initiation temperature rises due to the rise of the melt formation temperature in the wustite core and the gas reduction degree rises by about $8 \%$. As the average composition has high basicity, the melting point of the slag rises, carburizing into metallic iron is delayed, and the melt-down temperature rises.

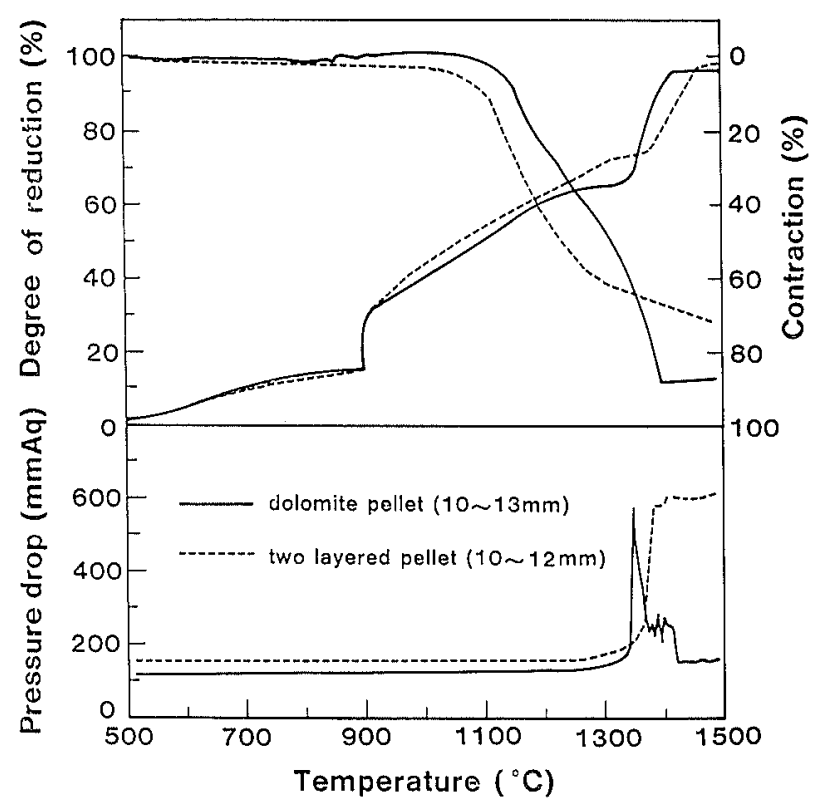

Fig. 16. Results of under-load reduction test for two-layers pellets.

\section{Conclusion}

We have shown the reduction retardation, carburization and melt-down mechanism of both pellets and sinter. The results obtained are as follows;

(1) Reduction retardation in pellets is attributed to the disappearance of the micropores caused by the sintering of iron under the presence of a liquid exuded from the wustite core.

(2) The carburization into metallic iron progresses mainly by contact with solid carbon. With the sinter, the contact between metallic iron and carbon is impeded until temperature rises since the melting point of $\mathrm{C}_{2} \mathrm{~S}$ formed by melting reduction is high, so that melt-down is delayed. Unlike sinter, pellets feature continuous contact between the metallic iron and carbon when the temperature exceeds $1300^{\circ} \mathrm{C}$ since the melting point of the melilite slag formed by melting reduction is low. As a result of this, carburization progresses, and melting-down occurs at a relatively low temperature.

(3) Reduction retardation of pellets was improved by adjusting the chemical composition of the core part having a high solidus temperature and the melt-down property was ameliorated by the increasing basicity of the entire pellet.

\section{REFERENCES}

1) M. Sasaki, K. Ono, A. Suzuki, Y. Okuno, K. Yoshizawa 
and T. Nakamura: Tetsu-to-Hagané, 62 (1976), 569.

2) K. Narita, M. Maekawa and H. Kanayama: Tetsu-toHagané, 66 (1980), 1860.

3) R. Nishida, O. Tsuchiya, T. Uenaka, T. Sato, K. Aketa and I. Nishida: Kobe Steel Eng. Rep., 34 (1984), No. 4, 28.

4) K. Inoue, T. Ikeda, T. Uenaka and M. Kanemoto: Tetsuto-Hagané, 68 (1982), 2441.

5) K. Sato, S. Suzuki, Y. Sawamura and K. Ono: Tetsu-toHagané, 68 (1982), 2215.

6) K. Inoue, T. Ikeda and T. Uenaka: Teisu-to-Hagané, 68 (1982), 2431

7) A. Okamoto, M. Naito, K. Ono, Y. Hayashi and Y. Inoue: Tetsu-to-Hagané, 72 (1986), 1529.

8) A. Muan and E. F. Osborn: Preprint of General Meeting of American Iron and Steel Institute, New York, May 2324, (1951).

9) W. C. Allen and R. B. Snow: J. Am. Ceram. Soc., (1955), 264.

10) G. Thaning: Ironmaking Steelmaking, (1976), No. 2, 57.

11) Blast Furnace Phenomena and Modelling, ed. by Comm. on Reduction within Blast Furnace, Joint Soc. on Iron and Steel Basic Research of Iron Steel Inst. Japan, Elsevier Applied Sci. Publ. Ltd., London, (1987), 414.

(Originally published in Tetsu-to-Hagané, 75 (1989), 2010, in Japanese) 